Marquette University

e-Publications@Marquette

Exercise Science Faculty Research and

Publications

Exercise Science, Department of

$5-2016$

\title{
Reactive Strength Index Modified Is a Valid Measure of Explosiveness in Collegiate Female Volleyball Players
}

Kristof Kipp

Marquette University, kristof.kipp@marquette.edu

Michael T. Kiely

Marquette University

Christopher Geiser

Marquette University, christopher.geiser@marquette.edu

Follow this and additional works at: https://epublications.marquette.edu/exsci_fac

\section{Recommended Citation}

Kipp, Kristof; Kiely, Michael T.; and Geiser, Christopher, "Reactive Strength Index Modified Is a Valid Measure of Explosiveness in Collegiate Female Volleyball Players" (2016). Exercise Science Faculty Research and Publications. 81.

https://epublications.marquette.edu/exsci_fac/81 


\title{
Reactive Strength Index Modified Is a Valid Measure of Explosiveness in Collegiate Female Volleyball Players
}

\author{
Kristof Kipp \\ Department of Physical Therapy, Marquette University, \\ Milwaukee, WI \\ Michael T. Kiely \\ Department of Physical Therapy, Marquette University, \\ Milwaukee, WI \\ Christopher F. Geiser \\ Department of Physical Therapy, Marquette University, \\ Milwaukee, WI
}

\begin{abstract}
Kipp, K, Kiely, MT, and Geiser, CF. Reactive strength index modified is a valid measure of explosiveness in collegiate female volleyball players. J Strength Cond Res 30(5): 1341-1347, 2016-The purpose of this study was to investigate the validity of the reactive strength index modified (RSImod) as a measure of lower body explosiveness. Fifteen female, National Collegiate Athletic Association Division I volleyball players performed vertical countermovement jumps (CMJs) while standing on a force plate. Each player performed $3 \mathrm{CMJ}$ s. The vertical ground reaction forces collected during each jump were used to calculate jump height, time to takeoff, time to peak force, peak force, peak rate of force development, and peak power; the latter 3 variables were all normalized to body mass. Reactive strength index modified was calculated as the ratio between jump height and


time to take-off. All variables, except for jump height, were then entered a factor analysis, which reduced the input data into 2 factors: a force factor and a speed factor. Although RSImod loaded more strongly onto the force factor, further analysis showed that RSImod loaded positively onto both force and speed factors. Visual analysis of the Cartesian coordinates also showed that RSImod loaded into the quadrant of greater force and speed abilities. These results indicate that the construct of RSImod, as derived from CMJ force-time data, captures a combination of speed-force factors that can be interpreted as lower body explosiveness during the CMJ. Reactive strength index modified therefore seems to be a valid measure to study lower body explosiveness.

\section{Introduction}

The countermovement jump (CMJ) is often used to assess the maximal dynamic performance of the extensor muscle groups of the lower extremity. ${ }^{14,15,23,24}$ The simplicity and reliability of the CMJ make it ideal for assessing cross-sectional differences and monitoring longitudinal changes in maximal dynamic performance in the practical setting. ${ }^{5,16}$ Although $\mathrm{CMJ}$ height provides perhaps the simplest and most direct measure of $\mathrm{CMJ}$ performance, a variety of other measures are frequently used to augment the analysis of $\mathrm{CMJ}$ performance and provide better insight into maximal dynamic performance. ${ }^{6-8}$ In particular, researchers have focused on the analysis of biomechanical measures that are acquired through force plate testing, which provides them with a much greater number and more detailed list of biomechanical variables that describe maximal dynamic performance and the movement dynamics of the CMJ.7,9,24,25 These biomechanical variables are typically calculated and derived from the force-time record of the CMJs. A drawback, however, is that the biomechanical analysis of force-time records may yield up to 30 separate, additional variables. ${ }^{1,2}$ The greater insight into movement biomechanics may thus reduce the interpretability of the acquired information.

In contrasts to the in-depth analysis of $\mathrm{CMJ}$ force-time records and the excess of variables, other researchers have proposed the use of simpler performance indices, such as the reactive strength index modified (RSImod). ${ }^{3,4,7,19-21}$ Reactive strength index modified is a simplified measure that is calculated as the ratio of CMJ height to time to take-off (TtT). In lay terms, the RSImod thus indicates how much jump height $(\mathrm{JH})$ one achieves for how much time it takes one to flex and extend the legs during the $\mathrm{CMJ}$. Overall, the RSImod is 
generally purported to represent or measure the level of "explosiveness" that an athlete possesses. 3,4,7,20,21 Although the formula used to calculate RSImod and its relationship to other forcetime variables provides theoretical rationales that RSImod measures explosiveness, these rationales may be limited by a lack of statistical or scientific validation because of failure to account for the multivariate (i.e., principal component) structure of $\mathrm{CMJ}$ force-time data and resultant losses of relevant information.

More recently, sport scientists have used a factor analysis approach to investigate the principal component structure of CMJ force-time variables. ${ }^{9,11,12,17}$ Such an approach generally reduces the number of input variables, in this case from $\mathrm{CMJ}$ force-time series, into smaller sets of uncorrelated "factors" that capture unique theoretical aspects representative of the input data (e.g., physiological variables related to $\mathrm{CMJ}$ performance). Factor analyses of $\mathrm{CMJ}$ force-time records typically reduce discrete $\mathrm{CMJ}$ force-time variables, such as peak force (PF), power, and time to peak force (TtPF), into 2 primary factors. ${ }^{9,11,12,17}$ Each subject is subsequently assigned a score for each factor to represent how much of a given factor is present in his/her CMJ force-time profile. The 2 resulting factors often represent a "force" factor and a "speed" factor, which means that each subject receives a concomitant force and speed score. The attractiveness of this procedure is that it delineates a large number of variables that are derived from $\mathrm{CMJ}$ force-time records into 4 easy to understand jump profiles, i.e., profiles with either high or low scores on each of the 2 factors. ${ }^{9,11,12}$ These jump profiles can thus be characterized as either a high force and fast jump profile, a low force and fast jump profile, a high force and slow jump profile, or finally a low force and slow jump profile. More importantly to practitioners is that these analyses successfully identified crosssectional differences between male and female athletes and between athletes from sport-specific backgrounds. ${ }^{12,17}$

Based on available data, one could hypothesize that high force and fast CMJ profiles should be characterized by greater RSImod, if the latter truly does provide a measure of explosiveness. If this is indeed the case, RSImod may provide a sensible approach to investigating the biomechanical variables that describe maximal dynamic performance and the movement dynamics of the CMJ. The 
purpose of this study was to investigate the validity of the RSImod as a measure of lower body explosiveness. The rationale was that if RSImod is to provide a useful measure in the assessing and monitoring of athletes, then its construct validity needs to be established through statistical methods. We hypothesized that (a) a factor analysis of CMJ biomechanical data would reduce all input data into a force and speed factor and (b) if RSImod represents a measure of explosiveness, it would load onto both of these factors.

\section{Methods}

\section{Experimental Approach to the Problem}

To examine the validity of RSImod as useful measure of explosiveness, subjects were recruited and asked to perform multiple CMJs. Data derived from CMJ force-time records were then entered a factor analysis. It was expected that the analysis would reduce the input data into a force and speed factor and that RSImod would load onto both of these factors, which would indicate that it captures a multifactorial combination of force and speed and thus represents a measure of explosiveness.

\section{Subjects}

Fifteen female, National Collegiate Athletic Association (NCAA) Division I (DI) volleyball players (mean \pm SD; age: $20.4 \pm 1.0$ years; height: $1.81 \pm 0.10 \mathrm{~m}$; body mass: $71.6 \pm 7.6 \mathrm{~kg}$ ) were recruited for this study. All subjects were actively engaged in a yearly training program that involved jumping exercises, such as the $\mathrm{CMJ}$, and were tested during their preseason training phase. The study was approved by the University's institutional review board, and all subjects provided written informed consent before beginning any data collection. The study conforms to the Code of Ethics of the World Medical Association (approved by the ethics advisory board of Swansea University) and required players to provide informed consent before participation. 
NOT THE PUBLISHED VERSION; this is the author's final, peer-reviewed manuscript. The published version may be accessed by following the link in the citation at the bottom of the page.

\section{Procedures}

\section{Testing Protocol}

Before testing, all subjects engaged in their sport-specific warm-up routines and their individual one-on-one skill session for that day. Subjects then reported for CMJ testing before moving onto their strength and conditioning session. All subjects were familiar with $\mathrm{CMJ}$ testing procedures. Briefly, explicit instructions for $\mathrm{CMJ}$ included for athletes to place their hands on their hip in an akimbo position, squat down to their preferred depth, and jump as high as possible. Each subject was given several warm-up jump attempts that progressed from submaximal to maximal intensity (i.e., height). Subjects then performed $3 \mathrm{CMJs}$ with maximal effort and approximately 20-30 seconds rest between jumps.

\section{Data Collection}

Kinetic data were acquired from a force plate (Kistler Quattro; Kistler Inc., Winterthur, Switzerland). Kinetic data were sampled at $500 \mathrm{~Hz}$. The vertical component of the ground reaction force was saved from each jump and stored for later analysis. After testing, these data were exported into Microsoft Office (Microsoft, Redmond, WA, USA) excel spreadsheets for further processing.

\section{Data Processing}

A custom-written MATLAB software program (MatLab; The MathWorks, Inc., Natick, MA, USA) was used for all data processing steps. The raw kinetic data were imported, and a fourth-order Butterworth filter was used to filter the data at $12 \mathrm{~Hz}$. The filtered kinetic data from each jump were used to calculate $\mathrm{JH}, \mathrm{TtT}$, TtPF, concentric-phase extension range (ConROM), PF, peak rate of force development (PRFD), and peak power (PP) (Figure 1). Jump height was calculated based on the time that each subject spent in the air during each CMJ. ${ }^{13}$ The TtT was calculated as the difference between the point of take-off (i.e., when the ground reaction force reached 0 $\mathrm{N}$ ) and the point of $\mathrm{CMJ}$ movement initiation, as defined by visual inspection of the first decrease in the force-time record (Figure 2). The TtPF was calculated as the difference between the point of PF during the $\mathrm{CMJ}$ and the visual point of $\mathrm{CMJ}$ movement initiation. The ground reaction force data were numerically integrated once to calculate center-of-mass (COM) velocity and twice to calculate COM 
position; in each case, the integration constant was set to zero. ${ }^{24}$ From the COM position, the ConROM was measured (i.e., difference between COM at take-off and the lowest COM position). Peak power was calculated as the product between the instantaneous ground reaction forces and the COM velocities. ${ }^{24}$ The PRFD was calculated as the maximal first derivative of the ground reaction force time-series data. ${ }^{24}$ Peak force, PRFD, and PP were all normalized to body mass. Reactive strength index modified was calculated as the ratio between $\mathrm{JH}$ and TtT. The 3-trial averages of all variables were calculated and used for statistical analysis.

\section{Statistical Analyses}

The intraclass correlation coefficient (ICC) was calculated for all selected variables to establish test-retest reliability. Preliminary analysis of the Kaiser-Meyer-Olkin criterion gave a value of 0.639 and a significant Bartlett's test of sphericity. A factor analysis was therefore deemed appropriate given the input data. Time to take-off, TtPF, ConROM, PF, PRFD, PP, and RSImod were all considered for a factor analysis. ${ }^{9}$ A correlational analysis showed that ConROM did not correlate well with other variables and was thus dropped from further analysis. All remaining variables were then entered the factor analysis. ${ }^{9,11,12,17}$ The factor analysis used a principal component procedure to extract factors from the correlation matrix of the input data. The extracted factors were rotated with a varimax rotation. The eigenvalues of each extracted factor and the scree plot were used to screen the number of extracted factors. Given that factor analyses typically require larger data sets, small coefficients $(<0.50)$ were suppressed to provide a more conservative interpretation of the results. All statistical analyses were performed in SPSS 22.0 (IBM Corporation, Somers, NY, USA).

\section{Results}

\section{Descriptive Data}

The descriptive data for all biomechanical CMJ force-time variables are presented in Table 1 . Intraclass correlation coefficient data for the dependent variables were 0.82 for PRFD, 0.89 for TtT, 0.86 for TtPF, 0.96 for PF, and 0.96 for PP. 
NOT THE PUBLISHED VERSION; this is the author's final, peer-reviewed manuscript. The published version may be accessed by following the link in the citation at the bottom of the page.

\section{Factor Analysis}

The communalities for the input variables values to the factor analysis ranged from 0.64 for PRFD to 0.95 for RSImod, which indicated high reliability of the model. The factor analysis itself yielded 2 factors (Figure 3). The first factor accounted for $47.2 \%$ of the variance in the data set and included high loadings from the variables of TtT (0.92), TtPF (0.94), PRFD (-0.78), and RSImod ($0.50)$. The second factor accounted for $38.7 \%$ of the variance in the data set and included high loadings from the variables of PP (0.96), PF (0.80), and RSImod (0.84) (Figure 3).

\section{Discussion}

The purpose of this study was to investigate the validity of the RSImod as a measure of lower body explosiveness. We hypothesized that a factor analysis of biomechanical CMJ force-time data would result in the extraction of a force and a speed factor and that RSImod would load onto both factors, which would validate it as a conceptual measure of explosiveness. The results from this study supported our hypotheses in that 2 factors were extracted and that RSImod loaded onto both of them. Reactive strength index modified therefore seems to be a valid measure of lower body explosiveness and would seem to be a useful and meaningful measure that can be used in future studies.

Similar to other studies, the factor analysis extracted 2 factors that accounted for a cumulative total of $85.9 \%$ of the total variance between the variables calculated and derived from the CMJ force-time record.9,11,12,17 The first factor captured $47.2 \%$ of the variance and included the variables TtT, TtPF, PRFD, and RSImod. The second factor captured $38.7 \%$ of the variance and included the variables PP, PF, and RSImod. Based on the types of force-time variables and their directionality in how they loaded onto the individual factors, it seems that the first factor could be described as a "speed" factor and the second as a "force" factor. As illustrated by the factor loadings, RSImod does indeed seem to capture mechanical characteristics that are related to both factors (i.e., force and speed). Given that RSImod loaded onto the force and speed factor, this measure does seem to provide a conceptual measure of explosiveness. It should be noted, however, that RSImod did load more strongly onto the force factor 
than the speed factor, which may indicate that RSImod is more strongly associated with strength capabilities than speed capabilities. The fact that other researchers have noted that vertical jump performance and biomechanical variables are strongly linked to maximal absolute, relative, and isometric strength reiterates this finding. ${ }^{4,10,18,22}$

Aside from the analysis of the factor loadings, visual inspection of the Cartesian coordinates with respect to the axes and quadrants, the data also support the concept that RSImod captures a quality related to explosiveness. ${ }^{7,19,20}$ Based on the direction of the factor axes and the respective force and speed capabilities captured by each, the quadrants of the Cartesian coordinates delineated between 4 types of jump profiles: high force and fast jump, low force and fast jump, high force and slow jump, and finally low force and slow jump. The term speed-strength is often used to describe "power" or explosiveness based on conceptual interpretation between the combinations of the terms speed and strength. Given that the coefficients (i.e., Cartesian coordinates) of RSImod place it into the quadrant of a $\mathrm{CMJ}$ profile characterized by "high force and fast jumps," it can therefore be believed as a measure of speed-strength or alternatively explosiveness.

Given that RSImod is a simple and valid measure of explosiveness, it would seem to be an excellent variable to assess and monitor lower body performance. Although there is a dearth of longitudinal data on the use of RSImod in the practical setting, crosssectional studies indicate that, for example, RSImod varies between athletes who play different positions, relates to other measures of force development, and differs between different types of plyometric exercises. 3,4,7 More specifically, in a sample of baseball players, the RSImod values were greater in position players than in pitchers, which highlights that RSImod can capture positional differences that reflect diverse physical demands. ${ }^{3}$ Furthermore, RSImod is correlated to maximal strength, as measured during the isometric mid-thigh pull, in a broad cross section of collegiate athletes. ${ }^{4}$ Reactive strength index modified also differs between various plyometric exercises, such as the $\mathrm{CMJ}$, the squat jump, and the tuck jump, which indicates that it offers a dependable method to assess and rank the intensity of these exercises. ${ }^{7}$ In addition, RSImod also seems to provide a better 
measure of stretch-shortening cycle function than other commonly used measures, such as the prestretch augmentation percentage or eccentric utilization ratio. ${ }^{21}$ The superiority of RSImod over these other measures is based on the fact that its calculation includes a timing component. ${ }^{21}$ Given that RSImod loaded onto the speed factor obtained from the factor analysis, the current results corroborate this notion. The results from this study, in combination with the findings of previous research, therefore indicate that RSImod seems to be a robust measure of lower body explosiveness.

The results from this study should be interpreted in light of a few limitations. First, the sample of subjects in this study consisted entirely of female, NCAA DI volleyball players. The generalizability of the results may therefore be limited to that population and sport, and not necessarily to others. A second limitation may lie in the small sample size for the purposes of the statistical analysis, especially the factor analysis, which often requires large sample sizes to provide interpretable data. To address this limitation, the factor analysis procedure was deliberately adjusted to report only variables with large coefficients to reduce the risk of incorrectly loading variables onto factors and incorrectly interpreting the results. A further limitation is that countermovement depth during the eccentric phase of the CMJ was not controlled. In addition, the onset of movement initiation was made based on visual inspection, which may decrease the accuracy and affect temporal force-time variables. However, given the high ICC values for all dependent variables, this may not be a large source of measurement error. Another point to consider, perhaps in future investigations, is that the factor analysis only included a few of the most commonly used variables that are traditionally used to describe CMJ performance. It is conceivable that including more or different variables, such as eccentric-concentric movement time ratio or force/velocity values at time of peak power, may affect the results.

\section{Practical Applications}

The results indicate that the RSImod, calculated as the ratio between CMJ height and TtT, is related to 2 conceptual factors related to the maximal dynamic performance and the movement dynamics of the CMJ: (a) a force factor and (b) a speed factor. The RSImod was represented by the force and speed factors, which indicated that the 
RSImod can therefore be believed as a measure of speed-strength, or alternatively explosiveness. Scientists and practitioners should therefore feel confident in using RSImod to assess and monitor lower body explosiveness.

\section{References}

1. Aragon-Vargas LF, Gross MM. Kinesiological factors in vertical jump performance: Differences among individuals. J Appl Biomech 13: 2444, 1997.

2. Aragon-Vargas LF, Gross MM. Kinesiological factors in vertical jump performance: Differences within individuals. J Appl Biomech 13: 4565, 1997.

3. Bailey CA, Suchomel TJ, Beckham GK, Sole CJ, Grazer JL. Reactive strength index-modified differences between baseball position players and pitchers. In: Proceedings of XXXII International Conference of Biomechanics in Sports. Sato, K., Sands, W.A. and Mizuguchi, S., eds. Johnson City, TN, 2014.

4. Beckham GK, Suchomel TJ, Bailey CA, Sole CJ, Grazer JL. The relationship of the reactive strength index-modified and measures of force development in the isometric mid-thigh pull. In: Proceedings of XXXII International Conference of Biomechanics in Sports. Sato, K., Sands, W.A. and Mizuguchi, S., eds. Johnson City, TN, 2014.

5. Cordova ML, Armstrong CW. Reliability of ground reaction forces during a vertical jump: Implications for functional strength assessment. J Athl Train 31: 342-345, 1996.

6. Dowling JJ, Vamos L. Identification of kinetic and temporal factors related to vertical jump performance. J Appl Biomech 9: 95-110, 1993.

7. Ebben WP, Petushek EJ. Using the reactive strength index modified to evaluate plyometric performance. J Strength Cond Res 24: 19831987, 2010.

8. Kibele A. Possibilities and limitations in the biomechanical analysis of countermovement jumps: A methodological study. J Appl Biomech 14: 105-117, 1998.

9. Kollias IA, Hatzitaki V, Papaiakovou G, Giatsis G. Using principal components analysis to identify individual differences in vertical jump performance. Res Q Exerc Sport 1: 63-67, 2001.

10. Kraska JM, Ramsey MW, Haff GG, Fethke N, Sands WA, Stone ME, Stone $\mathrm{MH}$. Relationship between strength characteristics and unweighted and weighted vertical jump height. Int J Sports Physiol Perform 4: 461-473, 2009. 
NOT THE PUBLISHED VERSION; this is the author's final, peer-reviewed manuscript. The published version may be

accessed by following the link in the citation at the bottom of the page.

11. Laffaye G, Bardy BG, Durey A. Principal component structure and sportspecific differences in the running one-leg vertical jump. Int J Sports Med 5: 420-525, 2007.

12. Laffaye G, Wagner PP, Tombleson TI. Countermovement jump height: Gender and sport-specific differences in the force-time variables. J Strength Cond Res 4: 1096-1105, 2014.

13. Linthorne NP. Analysis of standing vertical jumps using a force platform. Am J Phys 69: 1198-1204, 2001.

14. Markovic G, Dizdar D, Jukic I, Cardinale M. Reliability and factorial validity of squat and countermovement jump tests. J Strength Cond Res 18: 551-555, 2004.

15. Moir G, Sanders R, Button C, Glaister M. The influence of familiarization on the reliability of force variables measured during unloaded and loaded vertical jumps. J Strength Cond Res 19: 140-145, 2005.

16. Nuzzo JL, McBride JM, Cormie P, McCaulley GO. Relationship between countermovement jump performance and multijoint isometric and dynamic tests of strength. J Strength Cond Res 22: 699-707, 2008.

17. Panoutsakopoulos V, Papachatzis N, Kollias IA. Sport specificity background affects the principal component structure of vertical squat jump performance of young adult female athletes. J Sport Health Sci 3: 239-247, 2014.

18. Stone MH, O'Bryant HS, McCoy L, Coglianese R, Lehmkuhl M, Schilling B. Power and maximum strength relationships during performance of dynamic and static weighted jumps. J Strength Cond Res 17: 140147, 2003.

19. Suchomel TJ, Bailey CA, Sole CJ, Grazer JL, Beckham GK. Using reactive strength index-modified as an explosive performance measurement tool in Division I athletes. J Strength Cond Res 29: 899-904, 2015.

20. Suchomel TJ, Sole CJ, Bailey CA, Grazer JL, Beckham GK. A comparison of reactive strength index-modified between six U.S. Collegiate athletic teams. J Strength Cond Res 29: 1310-1316, 2015.

21. Suchomel TJ, Sole CJ, Stone MH. Comparison of methods that assess lower body stretch-shortening cycle utilization. J Strength Cond Res, 2015. Epub ahead of print.

22. Thomas C, Jones PA, Rothwell J, Chiang CY, Comfort P. An investigation into the relationship between maximum isometric strength and vertical jump performance. J Strength Cond Res, 2015 Jul 11. [Epub ahead of print] DOI: $10.1519 /$ JSC.0000000000001100. 
NOT THE PUBLISHED VERSION; this is the author's final, peer-reviewed manuscript. The published version may be accessed by following the link in the citation at the bottom of the page.

23. Vandewalle $H$, Pérès $G$, Monod $H$. Standard anaerobic exercise tests. Sports Med 4: 268-289, 1987.

24. Winter DA. Biomechanics and Motor Control of Human Movement. Hoboken, NJ: John Wiley \& Sons, 2005.

25. Young WB. Laboratory assessment of athletes. New Stud Athlet 10: 8996, 1995.

Key Words: biomechanics; vertical jump; power; factor analysis; principal components; construct validity 
NOT THE PUBLISHED VERSION; this is the author's final, peer-reviewed manuscript. The published version may be accessed by following the link in the citation at the bottom of the page.

\section{Images}

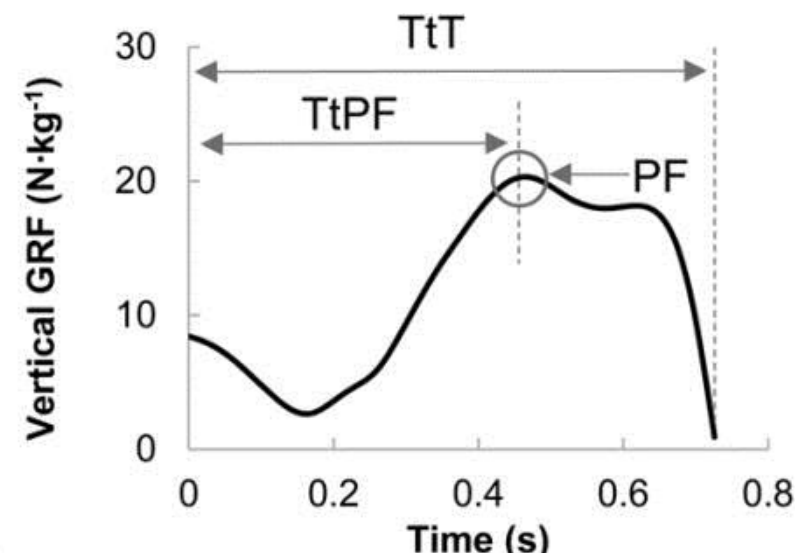

A Time (s)

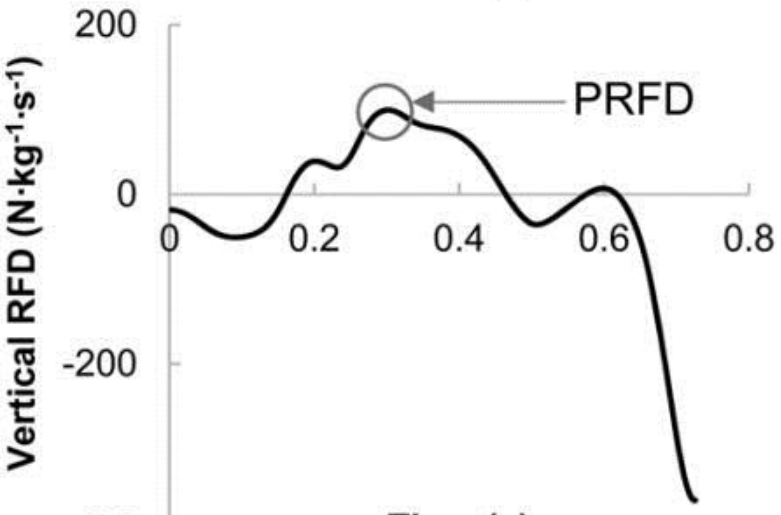

B $-400 \quad$ Time $(\mathbf{s})$

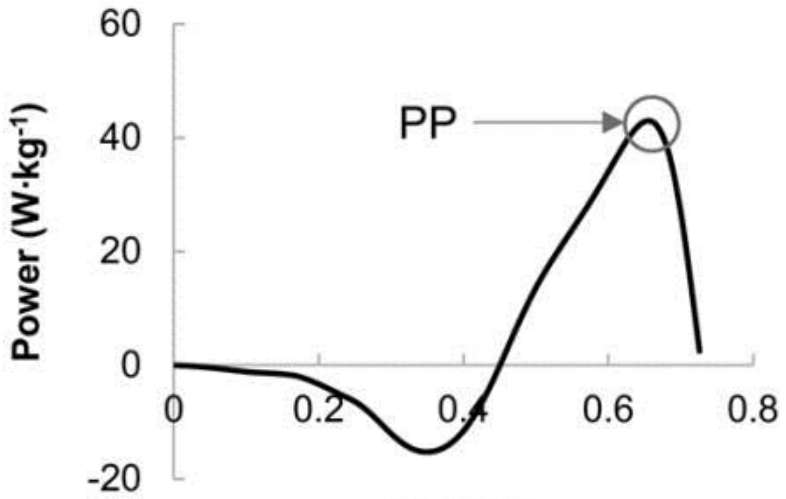

C

\section{Time (s)}

Figure 1. Countermovement jump force-time and calculated data. A) Vertical ground reaction forces $(\mathrm{GRF})$ : PF = peak force; TtT = time to take-off; TtPF = time to peak force. B) Vertical rate of force development (RFD): PRFD = peak rate of force development. C) Power output (power); PP = peak power. 
NOT THE PUBLISHED VERSION; this is the author's final, peer-reviewed manuscript. The published version may be accessed by following the link in the citation at the bottom of the page.

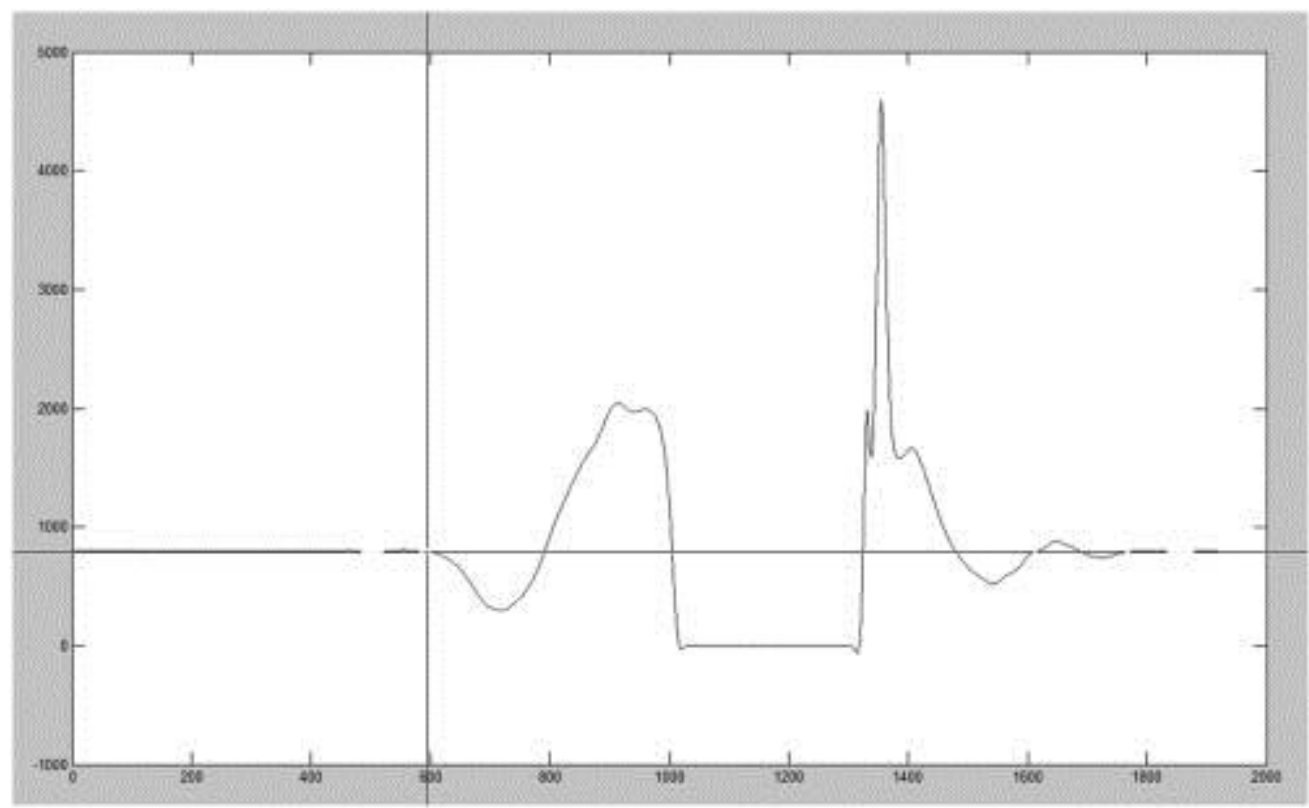

Figure 2. Sample force-time record with cross-hairs that were used to visually determine onset of movement initiation. The horizontal line of the cross-hairs was lined up with the stationary portion of the force-time record and the vertical line was lined up with the earliest decrease in ground reaction force, which was used to determine to the onset of movement.

\begin{tabular}{cccccccc}
\hline $\mathrm{JH}(\mathrm{m})$ & $\mathrm{TtT}(\mathrm{s})$ & $\mathrm{TtPF}(\mathrm{s})$ & $\operatorname{ConROM}(\mathrm{m})$ & $\mathrm{PF}\left(\mathrm{N} \cdot \mathrm{kg}^{-1}\right)$ & $\mathrm{PRFD}\left(\mathrm{N} \cdot \mathrm{kg}^{-1} \cdot \mathrm{s}^{-1}\right)$ & $\mathrm{PP}\left(\mathrm{W} \cdot \mathrm{kg}{ }^{-1}\right)$ & $\mathrm{RSImod}\left(\mathrm{m} \cdot \mathrm{s}^{-1}\right)$ \\
\hline $0.29 \pm 0.05$ & $1.010 \pm 0.121$ & $0.716 \pm 0.163$ & $0.45 \pm 0.03$ & $22.8 \pm 2.0$ & $148.8 \pm 52.8$ & $43.5 \pm 4.5$ & $0.29 \pm 0.07$ \\
\hline
\end{tabular}

$\cdot \mathrm{JM}=$ jump height; $\mathrm{TtT}=$ time to take-off; $\mathrm{T} \mathrm{TPF}=$ time to peak force; $\mathrm{ConROM}=$ concentric-phase extension range; $\mathrm{PF}=$ peak force; $\mathrm{PRFD}=$ peak rate of force development; $\mathrm{PP}=$ peak power: RSImod = reactive strength index modified

Table 1. Descriptive data (mean \pm SD) from extracted force-time record data during countermovement jumps of female, National Collegiate Athletic Association Division I volleyball players $(n=15)$.* 
NOT THE PUBLISHED VERSION; this is the author's final, peer-reviewed manuscript. The published version may be accessed by following the link in the citation at the bottom of the page.
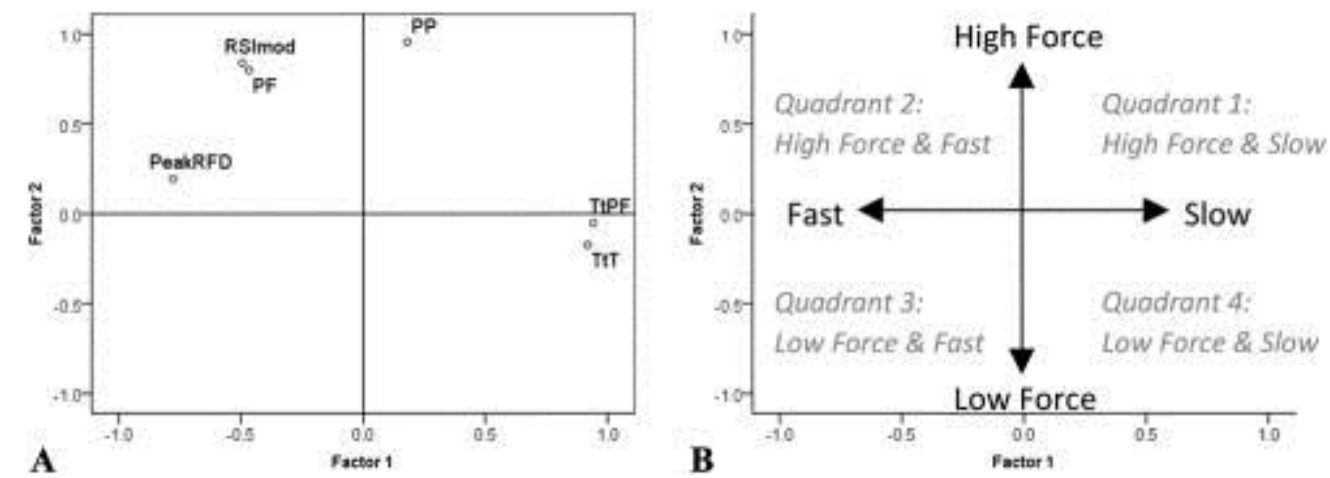

Figure 3. A) Cartesian coordinates (i.e., loading coefficients) of all input variables to the factor analysis graphed along the axis of the 2 extracted factors. Note how time to take-off (TtT), time to peak force (TtPF), peak rate of force development (RFD), and reactive strength index modified (RSImod) line up along factor 1 axis and capture speed-dependent variables, and how peak force (PF), peak power (PP), and RSImod line up along factor 2 axis and capture a force-dependent variables. B) Twodimensional representation of the force and speed factors, along with the 4 resulting types of countermovement jump profiles (in italics) that are captured by each quadrant of the graph. 